\title{
Problemas en la difusión de fonogramas desde instituciones de patrimonio y soluciones mediante procesos de gestión
}

\author{
Luis Fernando Ramos Simón* \\ Ignacio Miró-Charbonnier**
}

Artículo recibido:

27 de marzo de 2020

Artículo aceptado:

29 de junio de 2020

Artículo de revisión

\section{Resumen}

La gestión de los fonogramas en las instituciones de patrimonio plantea un sinfín de dificultades, sobre todo desde la perspectiva de los derechos de los titulares de las obras. El estudio describe un proceso de gestión documental, representado mediante diagramas de flujo, que está dirigido a resolver las principales dificultades a las que se enfrentan los gestores al momento de divulgar colecciones de fonogramas. En cuanto a la situación de los posibles titulares de derechos sobre los fonogramas, se analizan sucesivamente: a) los diferentes tipos de derechos sobre los documentos sonoros;

* Departamento de Biblioteconomía y Documentación, Universidad Complutense de Madrid, España Iframoss@ucm.es

** Departamento de Musicología, Universidad Alfonso X El Sabio, España

jmirocha@uax.es

INVESTIGACIÓN BIBLIOTECOLÓGICA, vol. 35, núm. 86, enero/marzo, 2021, México, ISSN: 2448-8321 pp. 45-71 
b) la duración de la protección de los derechos de los autores; c) la duración de los derechos conexos; y d) algunos problemas específicos de la gestión de derechos de autor en las instituciones de patrimonio. En conjunto, el estudio ofrece una herramienta para dar respuesta a la mayoría de los problemas que puede plantear en este entorno la difusión de los fonogramas, y demuestra las ventajas de disponer de una política de derechos de autor en las instituciones, tanto para la gestión interna de sus colecciones de fonogramas como para la difusión de éstas en la sociedad actual.

Palabras clave: Fonogramas; Grabaciones Sonoras; Derechos de Autor; Instituciones de Patrimonio Cultural

Problems in disseminating sound recordings from heritage institutions and solutions through management processes

Luis Fernando Ramos Simón and Ignacio Miró-Charbonnier

\section{Abstract}

Phonogram management in heritage institutions poses endless difficulties, especially as regards the rights of the owners of these works. The study presents a document management process, represented by a set of flowcharts, aiming to solve the main difficulties faced by managers willing to spread phonogram collections. The situation of the possible holders of phonogram rights is analyzed successively: a) the various types of rights on sound recordings; b) the duration of the protection of author's rights; $\mathrm{c}$ ) the duration of the related rights; and d) some specific problems of copyright management in heritage institutions. As a whole, the study offers a tool for responding to most of the problems posed by phonogram dissemination, and shows the advantages of having a copyright policy in institutions, both for the internal management of their phonogram collections and for dissemination of these in present-day society.

Keywords: Phonograms; Sound Recordings; Copyright; Cultural Heritage Institutions 


\section{Abreviaturas}

a/i/e: Artistas, intérpretes y ejecutantes. DPI: Derechos de propiedad intelectual. EGCD: Entidades de gestión colectiva de derechos. LPI: Texto legal vigente de Ley de Propiedad Intelectual.

\section{INTRODUCCIÓN}

- ste artículo pretende describir un proceso de utilidad para quienes cus- 1 todian colecciones de documentos sonoros y se enfrentan a la tarea de difundir algunas de estas piezas musicales y/o sonoras. Aunque el estudio está elaborado teniendo en cuenta el contexto español, queda muy ajustado a los convenios internacionales y a la legislación europea adoptada por España.

Una de las tareas más complejas que deben afrontar las instituciones de patrimonio cultural, además de las ligadas al proceso técnico documental (catalogación, clasificación, preservación, etc.), es la de resolver las incertidumbres legales que plantean la difusión y la preservación de las grabaciones sonoras o fonogramas.

En efecto, la tipificación legal de esos documentos en cuanto a difundirlos, incluso a pequeñas audiencias, resulta ser un asunto muy complicado. Además del número de sujetos que participan en la elaboración y difusión de un fonograma, hay dos aspectos muy importantes a considerar: por un lado, las grabaciones se gestaron en un mundo muy diferente del actual, y por eso mismo pueden hoy en día resultar atractivas para determinados públicos o situaciones no previstos inicialmente; por otro, la disponibilidad de nuevas tecnologías facilita el tratamiento novedoso de los documentos, lo cual puede suscitar enormes expectativas económicas. ${ }^{1}$

\section{EsTADO DE LA CUESTIÓN}

Para referirnos a los documentos sonoros, usaremos aquí la denominación de fonogramas, término elegido para designar a ese tipo de documento por

1 Pensemos, por ejemplo, en las grabaciones de jazz de la segunda o tercera décadas del siglo pasado, para las que puede darse la casualidad de que un revival de la moda de los años veinte haga virales algunas piezas musicales de hace un siglo, que ya sólo se encuentren disponibles en las instituciones de patrimonio cultural. 
la Ley de Propiedad Intelectual (LPI, 1996-2020) y por convenios internacionales (OMPI, 1971). La LPI los define como "toda fijación exclusivamente sonora de la ejecución de una obra o de otros sonidos" (1996-2020: art. 114.1). El concepto fue acuñado por las casas discográficas que impulsaron la Convención de Roma (1961), por la cual lograron protección internacional (Rodríguez Tapia, 2007: 645).

Los fonogramas implican información incorporada a un soporte de manera tal que pueda ser traducida en sonido mediante la sola participación de los aparatos adecuados. Éstos podrán ser de tipo mecánico, eléctrico, digital, o de cualquiera de sus posibles combinaciones. La información puede haber resultado, bien del proceso de "fijar" un determinado acontecimiento sonoro, o bien de otro proceso que no partía de un hecho sonoro pero que ha producido "algo" que podrá sonar cuando sea sometido a la transformación adecuada. El nombre de grabación suele aplicarse solamente al primero de esos dos tipos de proceso; debería servir también para el segundo, pues de ambos resultan documentos sonoros, en el sentido de "productores potenciales de sonido" (Ramos Simón y Miró-Charbonnier, s. a.).

En estos últimos años, el patrimonio cultural ha suscitado gran interés, especialmente en cuanto a su conservación y su digitalización. Una consecuencia directa de lo anterior ha sido la expresión "instituciones de patrimonio cultural", que ha tenido plasmación legal en una reciente Directiva del Parlamento Europeo (Parlamento Europeo, 2019). En ella, las instituciones que se consideran de patrimonio cultural son "una biblioteca o un museo accesibles al público, un archivo o una institución responsable del patrimonio cinematográfico o sonoro" (Parlamento Europeo, 2019: art. 2.3). Esa nueva Directiva señala que con la digitalización de ese patrimonio se puedan realizar distintos tipos de uso de los contenidos conservados en las instituciones de patrimonio cultural, por ejemplo, en el caso de obras descatalogadas o fuera de circuito comercial. Por ello, se las debe dotar de un conjunto de mecanismos que faciliten dichos usos, especialmente en lo que se refiere a instrumentos jurídicos y de gestión.

El resultado de mecanismos como los citados permitiría usos más sencillos de las colecciones, ya que las obras sonoras en soporte digital se prestan a un manejo más fácil para su difusión y su explotación. También serían muy tangibles las ventajas para los representantes de los titulares de derechos, por cuanto podrían tener un acceso más sencillo a las colecciones y aprovechar lo que ofrece la institución del patrimonio cultural para sus obras: promoción, estadísticas de uso, visibilidad, etc. 


\section{OBjetivos}

El propósito de nuestro trabajo puede expresarse mediante tres objetivos, que expresaremos comenzando con el más general y teórico, para llegar al de mayor concreción.

1. Animar a las instituciones a que alcancen un claro conocimiento de la situación de los derechos sobre sus colecciones, tanto en lo que se refiere a la autoría como en lo relativo a productores, intérpretes, y otros participantes. Ese conocimiento es fundamental para que cada institución tome decisiones seguras y fundamentadas en cuanto a difundir sus fondos sonoros.

2. Describir de manera detallada un proceso documental dedicado a examinar sistemáticamente los derechos que puedan existir sobre los fonogramas presentes en los fondos institucionales. La descripción deberá estar claramente articulada para que cada unidad documental pueda incluir el proceso en el conjunto de su gestión, averigüe qué limitaciones legales existen sobre sus documentos sonoros, y decida en qué medida los difundirá.

3. Incluir, como parte de la descripción del proceso mencionado, su representación mediante diagramas de flujo. Éstos servirán como herramienta de trabajo a las instituciones, facilitándoles la comprensión del proceso representado, y con ello la mejor adaptación a sus necesidades concretas. Los diagramas deberán sumar a la buena distribución espacial de sus elementos una condensación máxima de las frases utilizadas, para ser esquemas rápidamente comprensibles de las conexiones entre los distintos supuestos.

\section{Metodología}

La utilidad de los diagramas de flujo para describir y regular los procesos documentales no debe ser subestimada. Numerosos autores consideran que esos diagramas deben formar parte esencial de las actividades y procesos de gestión documental. Su uso es cada vez más frecuente al diseñar y documentar esa gestión; así lo demuestran documentos como el que describe los procesos clave y de soporte de la biblioteca de la Universidad de Alcalá (PKF Attest, 2014).

Por su parte, Arias Coello afirma que "las bibliotecas y otras unidades de información son tan eficientes como lo son sus procesos" (2013: 34), y por 
ello considera que para esas instituciones existen ciertos procesos clave, "que inciden, de manera significativa, en los objetivos estratégicos y que son críticos para el éxito de la biblioteca" (35). En consecuencia, "el personal de la biblioteca debe conocer, comprender y cumplir con los requisitos previamente establecidos [...] y debe comprender que las actividades [de cada proceso] deben realizarse con un grado de calidad que garantice que cada una de ellas es un valor añadido para el mismo" (34). Para que las instituciones lleven a cabo correctamente las actividades integrantes de los procesos, deberán articular un procedimiento, una "forma específica de llevar a cabo una actividad o un proceso" (35). La fijación de ese procedimiento consistirá en "documentos que contienen el objeto y el campo de aplicación de una actividad; qué debe hacerse y quién debe hacerlo; cuándo, dónde y cómo se debe llevar a cabo; qué materiales, equipos y documentos deben utilizarse; y cómo debe controlarse y registrarse" (35).

Dentro de esos procedimientos, encaminados a la correcta articulación del trabajo en las organizaciones, suele figurar expresamente la tarea de decidir y diseñar diagramas de flujo; por ejemplo, en el marco del diseño de un flujo de trabajo (Sundic, 2007: 63), o en el de la gestión basada en procesos (Arias Coello, 2013).

En el ámbito bibliotecario, son muchos los casos de utilización de diagramas de flujo para gestión documental. Un ejemplo relativamente sencillo, pero no poco ilustrativo, es el que representa un proceso de colaboración entre una fundación cultural y otras instituciones (Fundación Dialnet, 2011: 2). Ese lugar obligado de los diagramas de flujo, dentro de los documentos-guía que fijen los procedimientos de gestión, es precisamente el que proponemos para los diagramas que aquí ofreceremos, para el caso de instituciones cuya misión implique difundir las colecciones sonoras presentes en sus fondos.

Los procedimientos que fijen las prácticas de esas instituciones deberán ser ampliados con esos diagramas y con otros elementos adicionales, entre ellos: a) un mapa de procesos de la institución, incluyendo el proceso aquí propuesto sobre derechos de propiedad intelectual; y b) un conjunto de indicadores para medir la calidad de los procesos. Un mapa de procesos lo dan Salvador-Oliván y Fernández-Ruiz (2012: 314-316), al tratar de la accesibilidad en un servicio web de la administración pública. Para diseñar un sistema de gestión, primero identificaron los procesos, su secuencia e interacción, y luego representaron en diagramas de flujo las tareas, actividades y registros utilizados en cada proceso, reuniendo todo ello en un procedimiento. En cuanto a indicadores de calidad de la gestión documental, éstos y los diagramas de flujo son incluidos por Alcalde Martín-Calero (2010) al describir un modelo para evaluar y planificar funciones de archivos de administración local. 
Para el caso particular que nos ocupa, relacionado con la difusión de fonogramas, el mapa de procesos de cada institución interesada debería incluir lo correspondiente a un proceso como el aquí propuesto, para averiguar el estado de los derechos sobre sus colecciones sonoras. Indicadores de calidad de ese proceso podrían ser el número de fonogramas analizados, el porcentaje de fonogramas sujetos a derechos, el porcentaje de acuerdos de difusión alcanzados con los titulares de esos derechos y el porcentaje de licencias acordadas con entidades de gestión colectiva.

Apuntada la necesidad de trabajar posteriormente en esos otros elementos, nos dedicaremos ahora a la descripción de los cuatro diagramas de flujo (Anexo) del proceso documental que deseamos proponer.

\section{Elaboración de los Diagramas DE FLUjo}

El diseño general de nuestros diagramas y la ordenación particular de sus elementos se basan en la norma ISO 5807:1985-2019 sobre procesos de información y los símbolos y convenciones para varios tipos de diagrama, incluidos los de flujo (ISO, 1985-2019). Algunos detalles han sido adaptados a las necesidades concretas del caso, como la propia norma contempla. ${ }^{2}$ Resumiremos ahora lo fundamental de la forma de representación gráfica elegida.

Los diagramas incluyen en su parte superior uno o más puntos de partida de otras tantas cadenas de preguntas. Éstas se van situando por debajo, dentro de elementos con forma de rombo. De cada uno emergen por lo general dos flechas, que corresponden a una respuesta positiva y a otra negativa. Cada respuesta suele conducir a una nueva pregunta o a un elemento que contiene una conclusión sobre la viabilidad de la difusión pretendida. Las conclusiones se encierran en rectángulos de esquinas redondeadas y con fondo de diversa tonalidad: clara para las conclusiones marcadamente favorables, intermedia para las que implican gestiones posteriores, y oscura para las claramente desfavorables.

Pasamos ahora a describir diagrama a diagrama nuestra red de preguntas. Recomendamos tener a la vista los diagramas al progresar en la lectura del texto principal, e ir localizando en ellos los elementos descritos en cada momento. Esto facilitará la comprensión de los itinerarios que podrá seguir este proceso documental, cuando sea emprendido por las instituciones con el fin de averiguar las posibilidades de difusión de sus fonogramas.

2 Las secciones informativas de la Norma están disponibles en https://www.iso.org/obp/ui/\#iso:std:iso:5807:ed-1:v1:en (fecha de consulta: marzo 2020). 
En los fonogramas o grabaciones sonoras pueden concurrir diversos derechos de propiedad intelectual. Una primera diferenciación, representada sobre todo por el primero de nuestros diagramas, resultará de contemplar varios tipos de titulares de derechos: los autores (el compositor de la partitura, el traductor de un texto, el conferenciante, el entrevistador o entrevistado, el arreglista de una obra preexistente, etc.); los posibles artistas, intérpretes y ejecutantes, y, por último, pero no con menor importancia, el productor o productores del fonograma. Una segunda diferenciación se muestra en el segundo de los diagramas, y se refiere a las duraciones establecidas legalmente para proteger a los autores de las obras fijadas en el fonograma, mientras que el tercer diagrama se centrará en la duración de la protección de los derechos conexos o afines.

Por último, el cuarto diagrama atenderá varios aspectos, por lo general más complejos; entre ellos figuran la relación con las entidades de gestión de los derechos de gestión colectiva, la decisión sobre fonogramas huérfanos, la incorporación de fonogramas a programas de digitalización mediante licencias colectivas extendidas, y la incorporación de fonogramas en obras compuestas que, por esa condición, pueden obstaculizar la difusión de un fonograma.

En conjunto, se trata de situaciones difíciles de abarcar en su diversidad, como puede ser la decisión sobre una controversia en una historia oral, en la que pueden surgir discrepancias entre el entrevistador, los entrevistados, la familia o tribu representados, e incluso los trabajadores de la propia institución de patrimonio. Situaciones que por su singularidad son inabarcables en su casuística y que simplemente nos limitamos a apuntar.

Nos centraremos, por tanto, en los siguientes aspectos:

A) Derechos de los autores, derechos de los intérpretes y derechos de los productores de los fonogramas.

B) Duración de la protección de los derechos de autoría.

C) Duración de la protección de los derechos conexos.

D) Situaciones específicas, complejas y raras.

\section{Derechos de los autores, derechos de los intérpretes y derechos de los productores de los fonogramas (diagrama A)}

El primer diagrama de los cuatro que proponemos es clave para todos ellos, pues determina si el lector deberá examinar también alguno de los otros tres, 
y en caso afirmativo, en qué momento. Este diagrama representa fundamentalmente los posibles tipos de titulares de derechos de propiedad intelectual. La existencia y situación de esos titulares afectará a los fonogramas custodiados por las instituciones de la memoria.

La parte izquierda del diagrama A trata de los autores que pueden haber intervenido en la creación de una obra fijada en un fonograma. Es decir, "la persona natural que crea alguna obra literaria, artística o científica" (LPI, 1996-2020: art. 5.1). Esta persona puede no existir; ello sucede cuando el fonograma recoge lo que habitualmente se denomina "paisaje sonoro": sonidos de entornos industriales o urbanos; sonidos de los seres vivos, de la naturaleza inanimada, o producidos por fuentes mixtas; y otros contenidos similares. En todos esos casos, se considerará por lo general que no existen autores, ni intérpretes y ejecutantes, que sean identificables, por lo que la totalidad de los derechos corresponderá al productor de esos fonogramas. Tampoco se habrán de atribuir derechos de explotación a los autores cuando se trate de obras que han pasado al dominio público, tal como señala la Guía de la Convención de Roma (OMPI, 1982: 19).

Cuando sí sea posible considerar “autores” para un fonograma, habrá varias modalidades posibles de autoría, que podrán concurrir en una misma obra musical. En el caso de fonogramas musicales, por ejemplo, será posible distinguir entre compositores, letristas, adaptadores, y arreglistas. Si se trata de otras grabaciones habrá que analizar la autoría de entrevistadores, declamadores, conferenciantes, etc. Se debe tener también en cuenta el caso de los autores cuya obra no haya entrado en dominio público: es posible que el contenido de esas grabaciones sea objeto de una de las "excepciones" contempladas en la LPI. Ése sería el caso de discursos pronunciados en ámbitos parlamentarios o de corporaciones públicas.

Por último, en el caso de que sí proceda hablar de autores del fonograma en cuestión, será necesario plantearse si esos autores le han cedido al productor los derechos de explotación (A.2a). ${ }^{3}$ También puede suceder que el autor y el productor sean la misma persona. En caso contrario, es decir, cuando el autor o autores del fonograma sean distinta persona física que el productor o productores de éste, y además conserven sus derechos de explotación sobre el fonograma, sería necesario plantearse la vigencia de sus derechos (A.3c. Ver también sobre este aspecto el diagrama B).

3 En adelante, indicaremos de esta manera el elemento de los diagramas al que el texto se refiere en cada momento. La letra mayúscula denotará a qué diagrama nos referimos; el número, la fila de preguntas en ese diagrama, y la letra minúscula, el elemento de los situados en esa fila. 


\section{El productor de fonogramas}

Puede decirse que la figura de un productor es indisociable del concepto de fonograma; por ello, los derechos de esos productores serán la parte esencial del problema de la difusión de los fonogramas.

La evolución técnica que tiene lugar en el siglo XX convierte una representación sonora efímera en permanente. "Los inventos de la fonografía, del cinematógrafo y de la radiofonía, seguidos de su progresiva divulgación a partir del inicio del siglo XX iban a producir una revolución radical en los medios de que disponían los autores para comunicar al público sus obras" (OMPI, 1982: 11). En efecto, con el fonógrafo el trabajo interpretativo de los artistas pasó de ser fugaz a ser duradero, pero además ese trabajo podía reproducirse, utilizarse y ser usado indefinidamente. Ello tuvo también efectos contraproducentes: el uso indiscriminado de las grabaciones causaba graves daños profesionales, lo cual impulsó la aprobación de convenios internacionales para armonizar soluciones en torno a los llamados derechos conexos. Éstos afectaban de modo desigual a toda clase de artistas y a los productores, impulsores de una potente industria amparada por el desarrollo tecnológico, que a su vez generaba graves convulsiones en la profesión. La regulación que logra la Convención de Roma (1961) parte de la armonización de esos derechos conexos con los derechos de autor, de modo que la Convención no afecta a la situación jurídica de un titular de derecho de autor, si bien se reconoce que pueden ocurrir conflictos de intereses.

Decíamos más arriba que la LPI entiende por fonograma "toda fijación exclusivamente sonora de la ejecución de una obra o de otros sonidos" (19962020: art. 114.1). Esa misma ley define al productor de un fonograma como "la persona natural o jurídica bajo cuya iniciativa y responsabilidad se realiza por primera vez la mencionada fijación”, y añade que cuando esa fijación tiene lugar en el seno de una empresa, "el titular de ésta será considerado productor del fonograma" (1996-2020: art. 114.2). En términos muy similares se definen esos términos en la Convención de Roma (1961: art. 3, ap. b y c). Ambas figuras aparecen definidas también en el Convenio de Fonogramas (OMPI, 1971).

En concordancia con el papel otorgado por la LPI a la figura del productor de un fonograma, esa ley le concede varios derechos exclusivos. Así, se le reconocen los derechos de reproducción, comunicación pública y distribución. Derechos que podrán transferirse, cederse o ser objeto de concesión de licencias contractuales.

Además de los derechos concedidos al productor, deben tenerse en cuenta también, de manera paralela, los posibles derechos de explotación tanto 
de los posibles autores del contenido del fonograma, como de los artistas, intérpretes y ejecutantes (que abreviaremos en adelante como a/i/e) que hayan podido intervenir en su realización.

\section{Artistas, intérpretes y ejecutantes}

El tercer grupo de titulares que puede intervenir en el fonograma es el de a/i/e. La LPI entiende por artista, intérprete o ejecutante a "la persona que represente, cante, lea, recite, interprete o ejecute en cualquier forma una obra" (1996-2020: art. 105). Considera equiparables, a efectos de derechos de propiedad intelectual, a los directores de escena, para el caso de las representaciones teatrales, y a los de orquesta, para las musicales.

Lo primero que deberemos plantearnos en cuanto a esos artistas, intérpretes y ejecutantes es si ha habido intervención de ellos en el fonograma. En caso afirmativo, $\mathrm{y}$ al igual que se contemplaba para los autores, es pertinente saber si los a/i/e han cedido sus derechos al productor, o si son la misma persona que ese productor. Efectivamente, puede darse la circunstancia de que los a/i/e del fonograma sean distinta persona física que el productor o productores del fonograma, y que además conserven la vigencia de sus derechos, aspecto que resultará fundamental para conocer el alcance de los derechos del productor. Igualmente, se deberá tener en cuenta que los a/i/e pueden participar de forma colectiva en grupos (no incluye a solistas ni a directores), en cuyo caso habrá un representante que actuará por acuerdo mayoritario.

\section{Duración de los derechos de los titulares de la obra (diagrama B)}

El segundo bloque de preguntas, representado en el diagrama B, trata de la duración otorgada por la LPI a los derechos de los creadores de obras literarias, científicas o artísticas. La entrada de esas obras en dominio público, cuando haya una persona física como titular de derechos sobre ellas, sucede a los 70 del fallecimiento de esa persona, según la legislación uniforme en toda la Unión Europea, si bien en España sigue en vigor para parte de los casos el plazo de 80 años tras el fallecimiento del autor, por aplicación del principio de derechos adquiridos.

La forma más sencilla de aproximarse al problema es plantear si se puede conocer a los autores individuales del fonograma, en cuyo caso se toma como referencia la fecha de su muerte. Cuando se ignora este dato, se toma como punto de partida la fecha de publicación de la obra. Es decir, cuando la autoría de una obra plasmada en un fonograma no se conoce, la LPI aplica 
un plazo de 70 años desde la divulgación lícita del fonograma. Ese plazo podrá ser modificado si antes de su finalización se llega a conocer la autoría del fonograma.

Si, por el contrario, la autoría del fonograma sí es conocida, se hace necesario identificar cuántos autores hay. Recuérdese que esos autores podrán ser de un mismo tipo o de tipos distintos: compositores, arreglistas, guionistas, etc.

En el caso de que el autor del fonograma sea uno solo, es necesario plantearse si la fecha de fallecimiento es anterior al 7 de diciembre de 1987. Cuando esto se cumple, el plazo de protección otorgado al fonograma por la LPI es de 80 años a partir de su divulgación lícita. Para el resto de autores, es decir, para los aún vivos o los fallecidos el 7 de diciembre de 1987 o más tarde, el plazo de protección se reduce a 70 años. Así, para quienes fallecieron en 1988 la entrada de sus obras en dominio público no se producirá sino hasta 2059, es decir, dentro de casi 40 años.

De existir varios autores para el contenido del fonograma, hemos de plantearnos de qué tipo de autoría múltiple se trata. El diagrama B representa tres casos:

a. Obra colectiva. Según la LPI, se entiende por obra colectiva la que ha sido

creada por la iniciativa y bajo la coordinación de una persona natural o jurídica que la edita y divulga bajo su nombre y está constituida por la reunión de aportaciones de diferentes autores cuya contribución personal se funde en una creación única y autónoma, para la cual haya sido concebida sin que sea posible atribuir separadamente a cualquiera de ellos un derecho sobre el conjunto de la obra realizada. (1996-2020, art. 8.)

Es decir, que ha existido una persona física o jurídica que asumió para esa obra el papel de recopilador. En este caso, el plazo de protección otorgado por la LPI es de 70 años a partir de la divulgación lícita de la obra; y los derechos corresponden, salvo pacto en contrario, al coordinador que la ha editado y divulgado bajo su nombre.

b. Obra en colaboración. La LPI define obra en colaboración a la que es "resultado unitario de la colaboración de varios autores” (1996-2020: art. 7). En este tipo de obra, primero hay que averiguar si la aportación de cada uno de los autores consiste en una parte separable del resto, o no. Cuando lo sea, será forzoso considerar por separado cada parte/autor. El plazo de protección otorgado por la LPI para cada una de esas partes es de 70 años a partir de la divulgación lícita de esa parte, o desde el fallecimiento del autor de esa parte. 
Cuando las partes componentes de la obra no sean separables, el plazo de protección será computado desde la muerte del último autor superviviente (1996-2020: art. 28.1).

La LPI contempla expresamente el caso de las composiciones musicales con letra, donde distingue entre autor(es) de la letra y autor(es) de la composición musical; para esas obras, los derechos de explotación durarán hasta transcurridos 70 años desde la muerte del último superviviente de esos autores, siempre que su aportación fuera con motivo de la obra en colaboración.

En el caso de las obras anónimas, seudónimas y colectivas, mientras se mantengan como tales, los derechos de explotación durarán 70 años desde su divulgación. Por otro lado, cuando una institución cuente en su colección con obras que se hayan mantenido inéditas, llegará un momento en que éstas pasen a estar en dominio público, y si el autor no ha manifestado lo contrario, la institución podrá proceder a su difusión (LPI, 1996-2020: arts. 14 y 15). En tal caso, a toda persona que divulgue un fonograma inédito que se encontrara en dominio público, la LPI le otorga los mismos derechos que habrían correspondido a su autor, aunque con la importante diferencia de que el plazo de protección será "solamente" de 25 años a contar desde que se produzca la divulgación del documento sonoro en cuestión (1996-2020: art. 129.1).

En cuanto a la causa por la que un fonograma puede encontrarse inédito, se asume que tal situación es debida a una decisión expresa en tal sentido (o a la falta de decisión en sentido contrario), y se contemplan para ello dos supuestos: que la decisión proceda del autor o autores del contenido, o que proceda del productor del fonograma.

En el primero de los casos, se trata de un derecho moral que se reconoce a los autores de cualquier obra, incluida la que ha quedado fijada en un fonograma. Cámara Águila (2017: 128) entiende que, de los derechos morales, ése es el más estrechamente vinculado a los derechos de explotación. La vertiente "negativa" de ese llamado derecho de inédito es que impide la divulgación de la obra y el acceso del público a la misma, aparte de la posible reclamación de daños por el productor. En tal caso, la institución cultural custodia se ve imposibilitada para realizar cualquier acto de explotación de la obra, al menos en vida del autor. Fallecido éste, el ejercicio del derecho de divulgación corresponde a la persona natural o jurídica a la que el autor haya confiado tal derecho, mediante disposición de última voluntad; en ausencia de tal disposición, el derecho de divulgación pertenecerá a sus herederos. Una vez entrada la obra en el dominio público, o no habiendo ninguna persona o institución que se conozca que hayan sido facultadas por el autor para dicha divulgación, estarán legitimados para ejercer ese derecho el Estado, las Comunidades Autónomas, las corporaciones locales y las instituciones públicas culturales (LPI, 1996-2020: arts. 15, 16 y 40). 
Cuando se extinguen todos los derechos de explotación, la obra registrada en el fonograma entrará a formar parte del dominio público, puesto que nadie puede ya ni ejercer ni otorgar derecho alguno de explotación sobre la obra, pero si alguno de los elementos habitualmente protegibles del fonograma no estuviera todavía en dominio público (autoría, derechos de los artistas, intérpretes...), esos derechos deberán ser adquiridos previamente a la reproducción, distribución, o comunicación pública (Barberán Molina, 2018: 79). Cuando el fonograma estuviera integrado en la colección de una institución de patrimonio cultural, ésta podrá disponer de la obra con los mismos derechos que otorga la LPI a las obras en dominio público (19962020: art. 41). Si esa institución depositaria formara parte del sector público, podrá realizar las actividades sobre reutilización de la información del sector público que fueron previstas en la Ley 37/2007, actualizada en 2015; actividades que incluirían, entre otras posibilidades, la realización de acuerdos exclusivos de digitalización (Ley 37/2007: art. 6).

En el caso de que el productor del fonograma no publique un número suficiente de copias, ni haga comunicación pública del fonograma transcurridos 50 años, los a/i/e podrán resolver el contrato de cesión de derechos a aquél.

\section{Duración de los derechos conexos (diagrama C)}

Junto a la duración de los derechos de los autores, es fundamental determinar la duración de los derechos otorgados a actividades distintas de la creación -llamados conexos o afines-, dentro del conjunto de actividades relacionadas con las obras científicas, literarias y artísticas.

En el diagrama $C$ se encontrarán cinco partes, que corresponden a otras tantas categorías de posibles titulares de derechos. Esas partes son, de izquierda a derecha, las siguientes:

1) Artistas, intérpretes y ejecutantes (art. 105 y ss. LPI)

2) Responsables de producciones editoriales (art. 129 LPI)

3) Responsables de producciones de fonogramas (art. $114 \mathrm{y}$ ss. LPI)

4) Entidades de radiodifusión (arts. 126-127 LPI)

5) Ediciones musicales (art. 71 LPI)

Artistas, intérpretes y ejecutantes (a/i/e)

La LPI contempla un plazo inicial de 50 años desde el año de interpretación o ejecución en cuestión. El plazo se modifica si, antes de transcurrido ese lapso, 
se divulga lícitamente la grabación de esa interpretación o ejecución. En caso afirmativo, la duración de los derechos será de 70 años desde la realización del fonograma (LPI, 1996-2020: art. 112). En caso contrario, se mantiene el plazo concedido inicialmente (50 años desde la interpretación o ejecución).

\section{Parte relativa a los productores}

De manera provisional, la LPI (1996-2020: art. 119) contempla un plazo de 50 años desde el año de grabación del fonograma. Como ese plazo se modifica si antes de su finalización se comunica o publica lícitamente el fonograma, es necesario saber si una vez comenzado el plazo provisional de protección de la producción del fonograma, pero antes de terminar ese plazo, se ha comunicado o publicado lícitamente el fonograma (C.2b).

En caso afirmativo, la duración es de 70 años desde que el fonograma se comunica o publica lícitamente (lo que antes suceda, de esas dos posibilidades). En caso contrario, es decir, si no se comunica o publica lícitamente el fonograma antes de transcurridos 50 años desde el año de grabación del fonograma, este plazo se mantiene inalterado.

En consecuencia, si una institución cultural dispone de colecciones de fonogramas protegidos con derechos de terceros, deberá proceder de acuerdo con las prácticas y utilizaciones que permita la ley vigente de propiedad intelectual. Esto hará necesarias bien la solicitud de autorización a los titulares de esos derechos, o bien aplicar una excepción o límite si está contemplada en la LPI para el uso pretendido para el fonograma.

\section{Ediciones musicales}

Por el contrato de edición musical se conceden al editor los derechos de reproducción, distribución y, por lo general, de comunicación pública (LPI, 1996-2020: art. 71). Se rige por las reglas aplicadas al contrato de edición, salvo en algunas excepciones importantes. El plazo para la puesta en circulación de los ejemplares se alarga hasta los cinco años. Tampoco son de aplicación algunos de los postulados respecto a la resolución del contrato; es el caso de la venta a saldo o destrucción de ejemplares. No son de aplicación algunas de las causas de extinción de los contratos, como en el caso de la venta de todos los ejemplares y por el transcurso de 15 años desde que el editor estuvo en condiciones de reproducir la obra; por el contrario, la duración del contrato es la establecida por las partes. 
Esa circunstancia ha suscitado severas críticas por parte de la doctrina, en cuanto a la regulación del artículo 71 "que se ha prestado a todo tipo de corruptelas, extendidas en el mercado" (Rodríguez Tapia, 2007: 651).

\section{Difusión por las instituciones de patrimonio. Casos especiales (diagrama D)}

El cuarto y último diagrama de los que aquí proponemos se refiere al proceso que deberá seguirse, además de los que sean de aplicación de entre los representados en diagramas anteriores, cuando se desee difundir un fonograma, pero surjan uno o más problemas específicos.

Una vez realizados los análisis representados en los diagramas A, B y C, la institución deberá preguntarse si ha llegado a identificar y localizar a todos los titulares de derechos, antes de proceder a la difusión del fonograma. En especial podemos plantearnos qué problemas pueden surgir cuando es necesario contactar con las entidades de gestión de derechos.

La consulta de las tarifas vigentes de la Sociedad General de Autores y Editores de España (SGAE, http://www.sgae.es/es-es/sitepages/corp-ayudaP2.aspx?i=64) deja pocas dudas en cuanto a su propia legitimación para reclamar los derechos de reproducción, distribución y comunicación pública de sus asociados (LPI, 1996-2020: art. 150). Esa legitimación es proclamada ya en la primera página para exigir el cobro de tarifas también a las "entidades culturales", a las que se concede una reducción de tarifas, que apenas alcanza $5 \%$, y siempre que se cumplan una serie de requisitos, tales como acceso gratuito, sin patrocinadores, y suscripción previa de licencia, entre otros. Nada se menciona al respecto en dichas tarifas sobre la comunicación pública de obras en dominio público, o referido a la actuación de artistas intérpretes no vinculados a la entidad de gestión. A pesar de la importancia de la SGAE, en el ámbito de los fonogramas son AGEDI y AIE las dos entidades prominentes que gestionan esos derechos: "AGEDI es la única entidad de gestión en España que gestiona los derechos de los productores fonográficos, mientras que AIE es la única que administra los derechos de los artistas intérpretes o ejecutantes musicales de los fonogramas", según señala la Sección Primera de la Comisión de Propiedad Intelectual (SPCPI, 2018). Uno de los puntos de discusión de este documento alude a que las entidades de gestión, de conformidad con lo dispuesto en la disposición adicional segunda de la Ley 21/2014, "deben aplicar tarifas adecuadas a aquellos usuarios que tengan encomendada la gestión de servicios públicos de radio y televisión, carezcan de ánimo de lucro y tengan legalmente impuestas obligaciones de fomento de la cultura" (SPCPI, 2018). 
Reproduciremos a continuación algunas de las preguntas que las instituciones se plantean con frecuencia en relación con lo tratado por el diagrama $\mathrm{D}, \mathrm{y}$ añadiremos comentarios que pueden ayudar a responderlas.

- Una institución de patrimonio cultural ¿puede alquilar o prestar un fonograma? En cuanto al alquiler, nada impide que una institución alquile sus fonogramas si dispone de los derechos necesarios otorgados por los titulares de propiedad intelectual, tal como hemos observado en los apartados anteriores. Es evidente que el derecho alcanza a los fonogramas que hayan entrado en dominio público. En este sentido, puede servir de referencia el Centro de Documentación y Archivo de la SGAE, que en su página web ofrece el alquiler de materiales de orquesta para favorecer la programación de zarzuelas y música española y presenta, a modo de ejemplo, un extenso catálogo de autores, comenzando por Isaac Albéniz. Por su parte, el préstamo de fonogramas exige algunos requisitos más específicos para proceder a su gestión, al estar considerado como una excepción reservada a entidades sin ánimo de lucro o con finalidades docentes. Como es sabido, es una excepción al derecho de distribución que afecta, entre otras, a las obras depositadas en las fonotecas de carácter cultural o científico. La LPI (1996-2020: art. 37.2), y en particular el Real Decreto 624/2014, exigen una remuneración compensatoria para los titulares, aunque están exentas del pago las instituciones educativas y los pueblos de menos de 5.000 habitantes. Si los titulares de derechos perciben una remuneración, tiene poco sentido que se ponga reparo a este tipo de prácticas efectuadas con el más estricto respecto a los derechos de autor.

El mismo artículo de la LPI que menciona expresamente a las fonotecas entre las instituciones de titularidad pública o integradas en instituciones culturales que no precisan autorización de sus titulares para realizar préstamo de obras, también contempla la excepción para el caso de reproducciones con fines de investigación y conservación (LPI, 1996-2020: art. 37.1).

\section{- ¿Podemos proceder a la digitalización de fonogramas?}

El traslado de los contenidos en soporte analógico a nuevos soportes de tipo digital, por lo general para asegurar la supervivencia de esos contenidos y facilitar el acceso a los mismos, se ha convertido en un proceso clave para las instituciones que custodian fonogramas no nacidos digitales. Esa digitalización se presenta a veces como la solución por excelencia para la gestión de grabaciones sonoras.

La digitalización con fines de conservación está prevista como excepción en el ya mencionado art. 37 de la LPI (1996-2020). Una de las importantes 
novedades que incorpora la reciente Directiva sobre derechos de autor en Internet (Parlamento Europeo, 2019) es la regulación de los efectos de la digitalización de obras predigitales que se encuentren en dominio público. De una forma clara, el texto señala que "los Estados miembros garantizarán que ningún material resultante de un acto de reproducción de material de dominio público esté sujeto a derechos de autor u otros derechos afines, siempre y cuando tal reproducción sea fiel y tenga por objetivo la preservación del material original".

Con ese enunciado, se pretende dejar claro que la digitalización de un fonograma que se encuentre en dominio público no modifica la titularidad de los derechos que puedan estar asociados al mismo, ni genera nuevos derechos para ninguno de los participantes en esa digitalización, sean autores de fotografías de la carátula, diseñadores de software, restauradores, etc. Se pone fin así, o por lo menos se frena, una tendencia que estaba orientada a volver a conseguir protección para materiales de dominio público, mediante la atribución de originalidad a meros actos de reproducción servil.

\section{- ¿Cómo debemos actuar ante un fonograma buérfano?}

Uno de los problemas más severos que se derivan de los procesos de digitalización que mencionamos ut supra es el problema de las obras huérfanas. A esta cuestión - por merecer un tratamiento similar - se ha de unir la de la digitalización de fonogramas que ya están fuera de los circuitos comerciales, o sea, descatalogados. En uno y otro caso, las instituciones de patrimonio se enfrentan a problemas ligados a la ausencia de consentimiento de los titulares de derechos para llevar a cabo la digitalización. En el caso de obras huérfanas, ya reguladas en la legislación española (LPI, 1996-2020: art. 37 bis) pero sin haberse llevado a cabo aún su aplicación práctica, nos hallamos ante la circunstancia de que los titulares de derechos no están identificados, o lo están pero no así localizados, a pesar de haberse realizado previamente una búsqueda diligente. En el caso de las obras fuera de circuito comercial, situación ya regulada en la Directiva del Parlamento Europeo (2019) pero aún sin transponer a la legislación española, el problema que hay que resolver es cómo conseguir el consentimiento de las entidades de gestión para que sean digitalizadas obras fuera de los circuitos comerciales habituales.

Una vez transcurridos todos los plazos legales de protección que hayan afectado a un fonograma determinado que fue divulgado en algún momento, éste pasará a dominio público, por lo que es posible realizar diferentes ediciones literarias de los originales, y todo tipo de utilizaciones parciales, como la interpretación y grabación de algunas de las piezas musicales, tal como subraya Román Pérez (2011) a próposito del Misteri de Elche. Ello no 
suele conllevar declaración oficial alguna por parte de organismos públicos (simplemente se dice que las obras "caen" en dominio público) y tampoco se pide a la eventual institución custodia una declaración en ese sentido. Quedará por tanto a discreción de ésta si avisar o no públicamente de esa nueva circunstancia, cuando la institución proceda a divulgar los documentos así recalificados.

- Por último, ¿de qué derechos disponen los investigadores sobre los fonogramas depositados en la institución?

Es frecuente en este tipo de instituciones la presencia de estudiantes, docentes e investigadores que necesitan acceder a los fondos fonográficos y de otro tipo para avanzar en sus investigaciones y actividades docentes. Además de dar respuesta a una casuística general, pueden surgir un sinfín de preguntas concretas que no caben en un estudio de este alcance; pero sí se puede apuntar un enfoque general, en donde lo primero que hay que decir es que los cambios en la regulación legal por la presión de las nuevas tecnologías no dejan satisfechos ni a los titulares de los derechos ni a los beneficiarios de los límites.

En primer lugar, la excepción a los derechos de autor para la función de investigación es una de las prácticas más asentadas en el ámbito de la propiedad intelectual. Por un lado, las instituciones documentales (bibliotecas, fonotecas...) gozan de la excepción de reproducción de obras cuando ésta se realice sin ánimo de lucro, con fines de investigación. Por otro lado, mediante el derecho de cita, se considera lícita la inclusión, en una obra propia, de fragmentos ajenos (escritos, sonoros...) de obras ya divulgadas; y cuando su inclusión se realice a título de cita o para análisis o comentario, la utilización sólo podrá realizarse con fines de investigación o de docencia, en la medida justificada por ese fin, e indicando la fuente y el autor. Igualmente, mediante el derecho de ilustración está permitida la realización de actos de reproducción, distribución y comunicación pública de pequeños fragmentos de obras con fines de ilustración de actividades educativas o de investigación científica - con algunas restricciones, que pueden cambiar de un país a otro, y que se deben consultar en obras especializadas, como la de Carbajo y Curto (2018).

Es evidente que las tres modalidades de excepción mencionadas afectan al uso de los fonogramas. En ese contexto habría que descender a preguntas muy concretas, tales como de qué manera distinguir si un usuario hace investigación en lugar de un uso comercial o personal, qué usos pueden hacer los usuarios en un terminal dedicado, qué hacer con el asunto del cobro de las copias, etc.

Las respuestas a esas preguntas están para algunos supuestos claramente explicadas en las leyes; para otros, bastaría que los especialistas documentales de la institución aplicasen un conjunto de buenas prácticas, en algún caso tan sencillas como la de obligar al usuario a hacer una declaración formal sobre el 
alcance de la investigación y los medios de que va a disponer para llevarla a cabo. Con ello, se habrían evitado en muchas ocasiones un sinfín de problemas y consultas.

\section{CONCLUSIONES SOBRE LA DIFUSIÓN DE FONOGRAMAS} DESDE LAS INSTITUCIONES

La primera de las conclusiones principales de esta investigación es que para las instituciones resulta imprescindible conocer bien las distintas situaciones legales que se pueden presentar para sus colecciones sonoras; ese conocimiento se podrá apoyar en las descripciones ofrecidas en los distintos apartados: obras en dominio público, obras con derechos de autor de terceros, simple fijación sonora, etc. Sabiendo cada institución qué derechos posee y cuáles no, podrá establecer estrategias idóneas para difundir sus fonogramas.

Como segunda conclusión, diremos que la buena gestión de los posibles derechos sobre las colecciones sonoras de las instituciones de patrimonio requiere establecer y seguir unas directrices específicas, que se deben traducir en un proceso documental concreto y bien articulado. Directrices y proceso servirán como elemento esencial de transparencia, tanto internamente como hacia fuera. Internamente, la realización escrupulosa de un proceso documental bien estructurado ayudará a la institución a formular una política de gestión de fonogramas plenamente coherente con la misión que haya declarado, y le permitirá distinguir claramente entre sus actividades comerciales, si las tuviera, y las no comerciales. De cara al exterior, podrá poner de relieve los recursos disponibles, facilitando en gran medida su puesta en valor. Para conseguir esa transparencia interna y externa servirá de modelo el proceso que hemos ido describiendo, y que cada institución podrá adaptar a sus circunstancias y necesidades particulares.

Por último, destacaremos la utilidad que tiene la herramienta de tipo diagrama de flujo a la hora de representar el proceso documental citado, y luego realizarlo. Un diagrama (o conjunto de ellos) que sintetice correctamente las etapas y fases que componen un proceso, por complejo que sea, permitirá captar rápidamente sus rasgos fundamentales y facilitará en gran medida su puesta en práctica. En el caso de los diagramas que ofrecemos, confiamos en que su estado actual permitirá acelerar la gestión de las colecciones sonoras en cuanto a su difusión, y aumentar significativamente los resultados obtenidos hasta ahora. Además, el carácter modular de los diagramas permitirá modificarlos según lo recomiende su uso por las instituciones, y con ello ver mejorado el proceso de gestión que hemos descrito. 


\section{REFERENCIAS}

Alcalde Martín-Calero, Carlos. 2010. "Indicadores de gestión para los archivos de la administración local”. XII Jornadas de Gestión de la Información de SEDIC. Madrid, noviembre de 2010. Fecha de consulta: marzo de 2020. https://www.sedic.es/xii_jornadasgestion/textos/calcalde.pdf

Arias Coello, Alicia. 2013. Calidad de los servicios y satisfacción del usuario. Cuaderno de trabajo $n^{\circ} 11$. Madrid: Facultad de Ciencias de la Documentación, Universidad Complutense de Madrid. Fecha de consulta: marzo de 2020. https://www.researchgate.net/profile/Alicia_Arias2/publication/299387472_ Calidad_de_los_servicios_y_satisfaccion_del_usuario/links/56f2cd8408ae81582beba42e.pdf

Barberán Molina, Pascual. 2018. Manual práctico de propiedad intelectual, $2^{\text {a }}$ ed. Madrid: Tecnos.

Cámara Águila, Pilar. 2017. "El derecho moral del autor”, en Manual de Propiedad Intelectual, $7^{\mathrm{a}}$ ed., editado por Rodrigo Bercovitz Rodríguez-Cano, 127-142. Valencia: Tirant lo Blanch.

Carbajo, Fernando y M. Mercedes Curto. 2018. Propiedad intelectual y transferencia de conocimiento en universidades y centros públicos de investigación. Valencia: Tirant lo Blanch.

Convención de Roma. 1961. Sobre la protección de los artistas intérpretes o ejecutantes, los productores de fonogramas y los organismos de radiodifusión. Hecho en Roma el 26 de octubre de 1961. Fecha de consulta: abril de 2020.

https://www.wipo.int/edocs/lexdocs/treaties/es/rome/trt_rome_001es.pdf

Fundación Dialnet. 2011. Proceso de convenio con bibliotecas-instituciones. Logroño: Fundación Dialnet. Fecha de consulta: marzo de 2020.

https://dialnet.unirioja.es/publico/anexos/convenios_instituciones.pdf

ISO (International Organization for Standards). 1985-2019. ISO 5807:1985. Information processing - Documentation symbols and conventions for data, program and system flowcharts, program network charts and system resources charts. Fecha de consulta: abril de 2020.

https://www.iso.org/standard/11955.html

Ley 37/2007, de 16 de noviembre, sobre reutilización de la información del sector público. 2007. BOE (Boletín Oficial del Estado) N²76, de 17 de noviembre de 2007, 47160-47165. España. Fecha de consulta: abril de 2020.

https://www.boe.es/eli/es/1/2007/11/16/37/con

LPI (Ley de Propiedad Intelectual). 1996-2020. Real Decreto Legislativo 1/1996, de 12 de abril, por el que se aprueba el texto refundido de la Ley de Propiedad Intelectual, regularizando, aclarando y armonizando las disposiciones legales vigentes sobre la materia. Última actualización 2-3-2019. Fecha de consulta: marzo de 2020. https://boe.es/buscar/act.php?id=BOE-A-1996-8930

OMPI (Organización Mundial de la Propiedad Intelectual). 1971. Convenio para la protección de los productores de fonogramas contra la reprodución no autorizada de sus fonogramas. Ginebra: OMPI. Fecha de consulta: abril de 2020. https://www.wipo.int/edocs/pubdocs/es/wipo_pub_288.pdf 
OMPI. 1982. Guía de la Convención de Roma y del Convenio Fonogramas. Ginebra: OMPI. Reimpreso en 2003, versión española de José Miguel de Azaola. Fecha de consulta: abril de 2020 . https:/www.wipo.int/edocs/pubdocs/es/copyright/617/wipo_pub_617.pdf

Parlamento Europeo. 2019. Directiva (UE) 2019/790 del Parlamento Europeo y del Consejo de 17 de abril de 2019 sobre los derechos de autor y derechos afines en el mercado unico digital y por la que se modifican las Directivas 96/9/CE y 2001/29/CE. (Documento A8-0245/271, 20/03/2019). Fecha de consulta: abril de 2020. https://www.boe.es/doue/2019/130/L00092-00125.pdf

PKF Attest. 2014. Procesos clave y de soporte. Alcalá de Henares: Universidad de Alcalá. Fecha de consulta: marzo de 2020. https://biblioteca.uah.es/biblioteca/documentos/mapa_procesos.pdf

Ramos Simón, Luis F. e Ignacio Miró-Charbonnier. S. a. "La gestión y uso de los fonogramas en las instituciones de patrimonio cultural. Nuevos horizontes en la difusión de las colecciones sonoras". En Ética, LPI y grabaciones sonoras inéditas y etnomusicológicas, coordinado por José L. Maire y M. Jesús López Lorenzo. Madrid: AEDOM. En prensa.

Real Decreto 624/2014, de 18 de julio, por el que se desarrolla el derecho de remuneración a los autores por los préstamos de sus obras realizados en determinados establecimientos accesibles al público. 2014. BOE Nº 186, de 1 de agosto de 2014, 61523-61527. Fecha de consulta: abril de 2020. https://www.boe.es/eli/es/rd/2014/07/18/624

Rodríguez Tapia, J. M. 2007. “Derechos de los productores de fonogramas”, en Manual de Propiedad Intelectual, dirigido por José Miguel Rodríguez Tapia, 645668. Cizur Menor (Navarra): Editorial Aranzadi.

Román Pérez, R. de. 2011. "Obras del Patrimonio Cultural en la Ley de Propiedad Intelectual: Estudio de un caso concreto (el Misteri D'Elx)”. Revista de la Facultad de Ciencias Sociales y Jurídicas de Elche 1 (7): 109-122.

Salvador-Oliván, José-Antonio y María-Jesús Fernández-Ruiz. 2012. "Mapa de procesos de un sistema de gestión de accesibilidad en un servicio web de la administración pública: el Ayuntamiento de Zaragoza”. El profesional de la información 21 (3) (mayo-junio): 312-317. Fecha de consulta: marzo de 2020.

http://doi.org/10.3145/epi.2012.may.13

SPCPI (Sección Primera de la Comisión de Propiedad Intelectual del Ministerio de Cultura). 2018. Acuerdo, de 16 de noviembre de 2018, de la sección primera de la comisión de propiedad intelectual, por el que se da publicidad a la resolución, de 20 de septiembre de 2018, del procedimiento de determinación de tarifas solicitado por parte de la Asociación de Gestión de Derechos Intelectuales (AGEDI) y Artistas Intérpretes o Ejecutantes, Sociedad de Gestión de España (AIE). Fecha de consulta: marzo de 2020.

http://www.culturaydeporte.gob.es/cultura/areas/propiedadintelectual/mc/ s1cpi/resoluciones.html

Sundic, Teodor. 2007. "Etapas de la gestión documental y de procesos en las Administraciones Públicas”. Estrategia Financiera 238 (abril): 58-65. Fecha de consulta: marzo de 2020.

http://pdfs.wke.es/6/9/0/5/pd0000016905.pdf 
Para citar este texto:

Ramos Simón, Luis Fernando e Ignacio Miró-Charbonnier. 2021. "Problemas en la difusión de fonogramas desde instituciones de patrimonio y soluciones mediante procesos de gestión”. Investigación Bibliotecológica: archivonomía, bibliotecología e información 35 (86): 45-71. http://dx.doi.org/10.22201/iibi.24488321xe.2021.86.58254 


\section{Anexo. Diagramas sobre difusión y protección de fonogramas}

\section{Diagrama A}

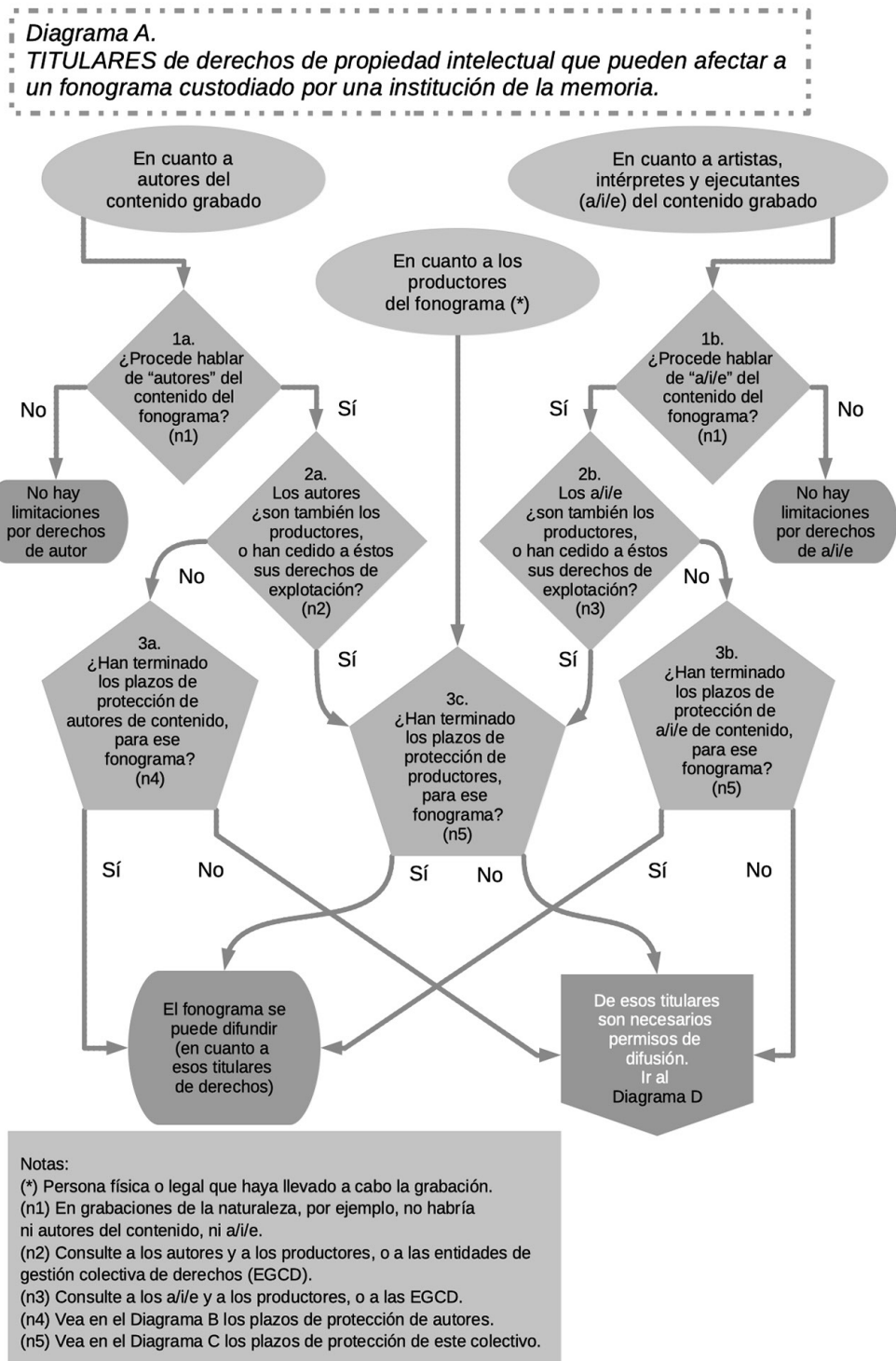




\section{Diagrama B}

Provisionalmente se aplica un plazo de protección de 70 años desde el año de la divulgación lícita

Diagrama B.

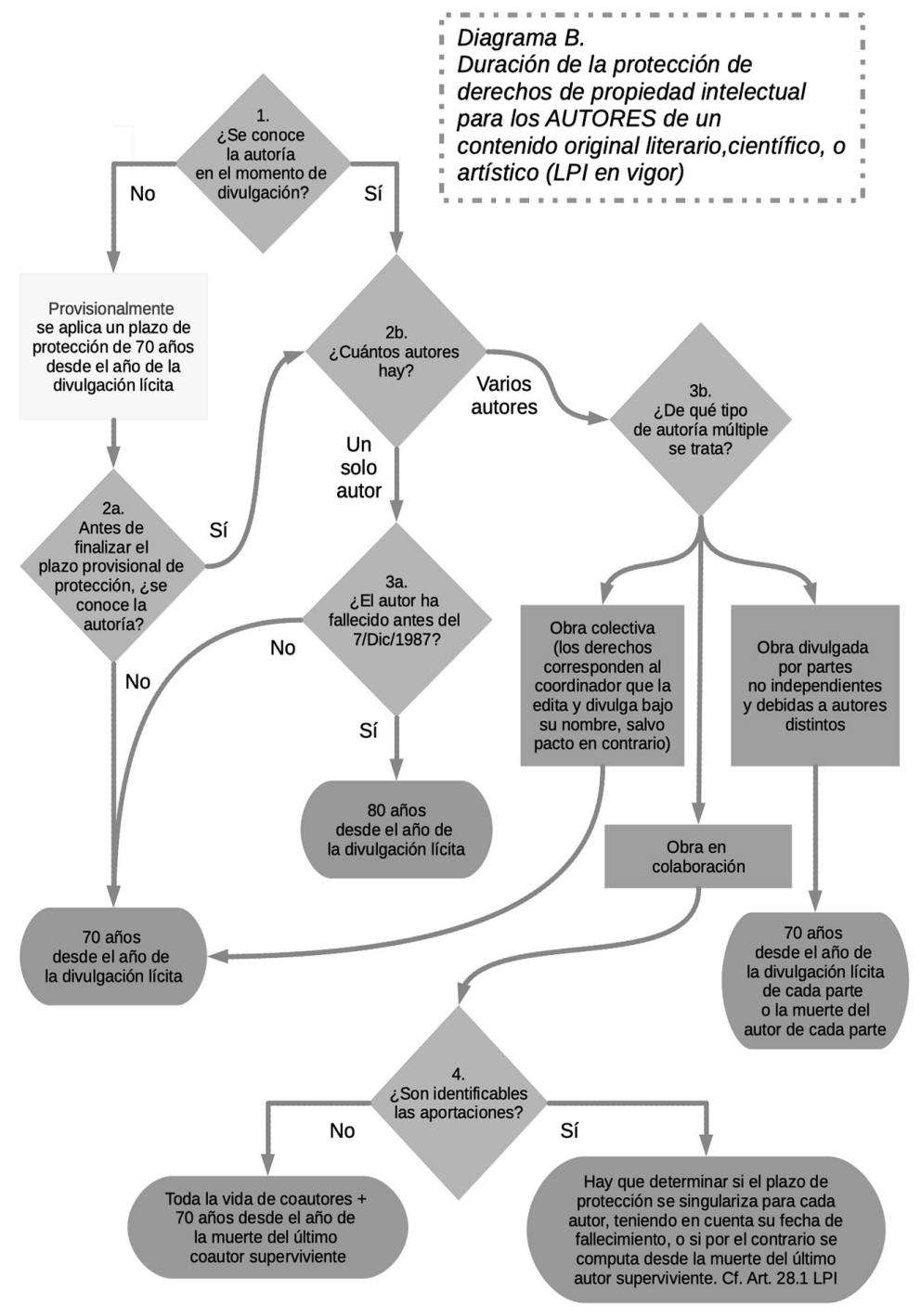

- derechos de propiedad intelectual

- para los AUTORES de un

" contenido original literario,científico, o

" artístico (LPI en vigor)

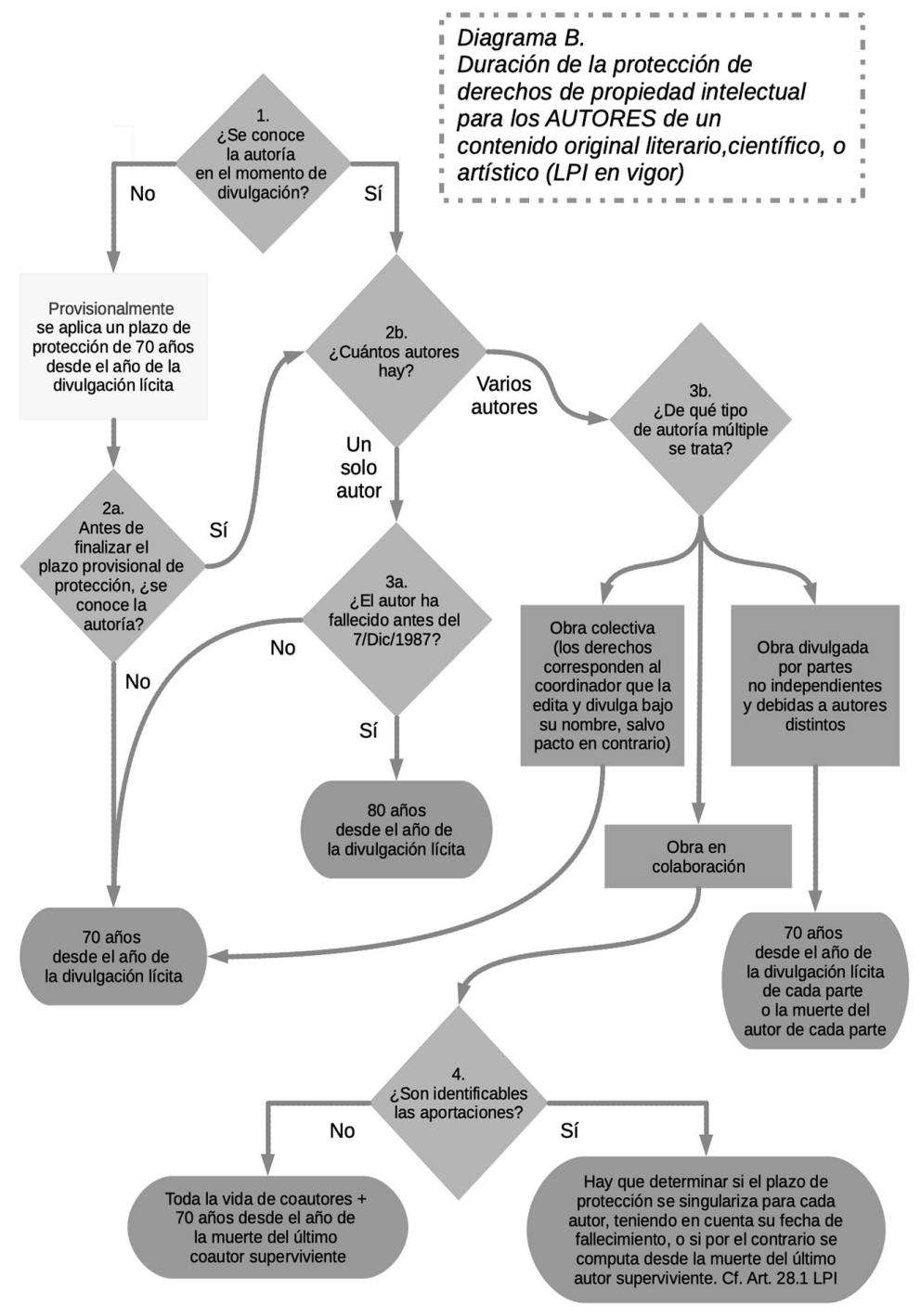

plazo provisional de

protección, ¿se

autoría?

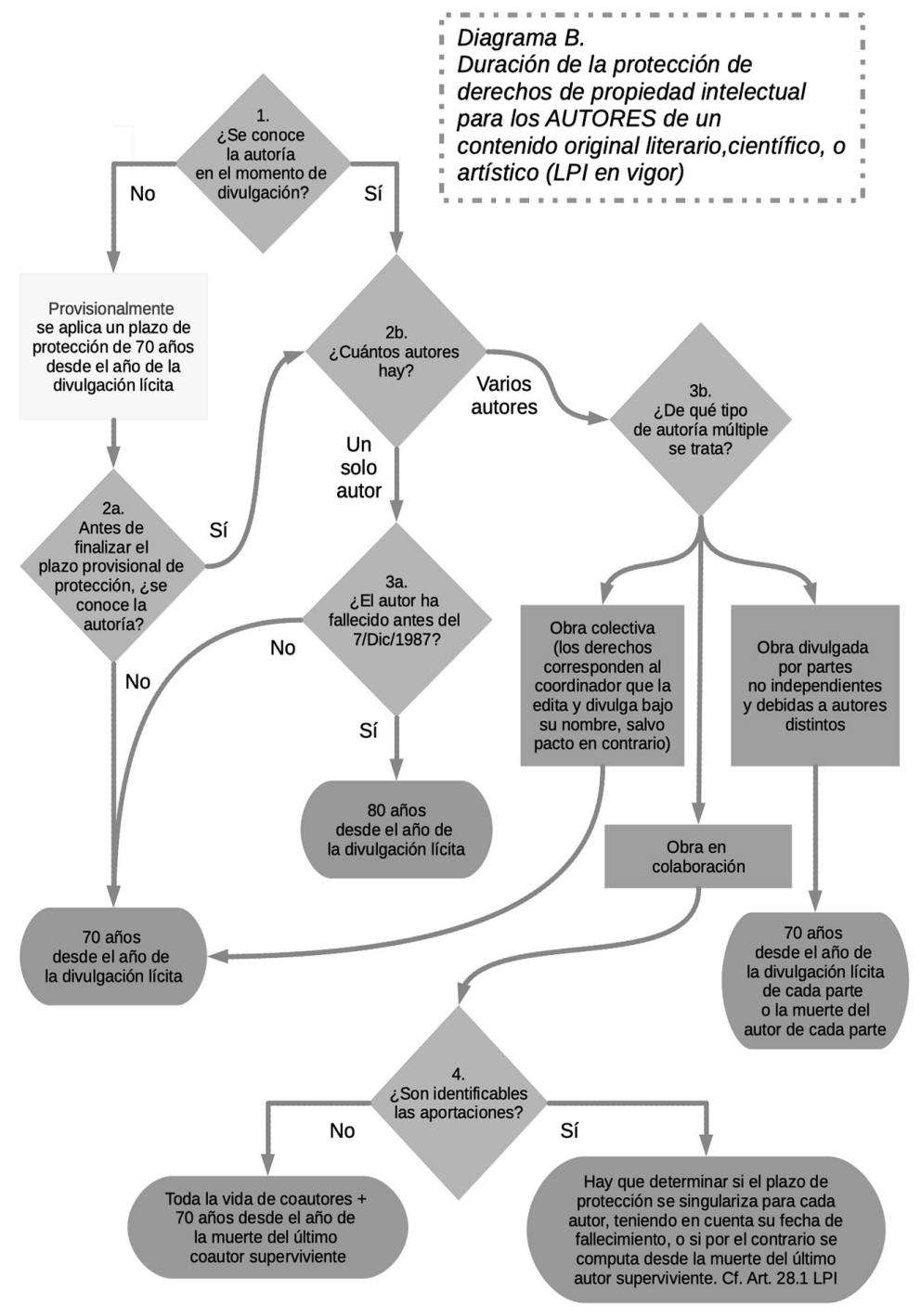

$3 a$.

$2 \mathrm{~b}$.
ántos autores

hay?

"

70 años

desde el año de

la divulgación lícita

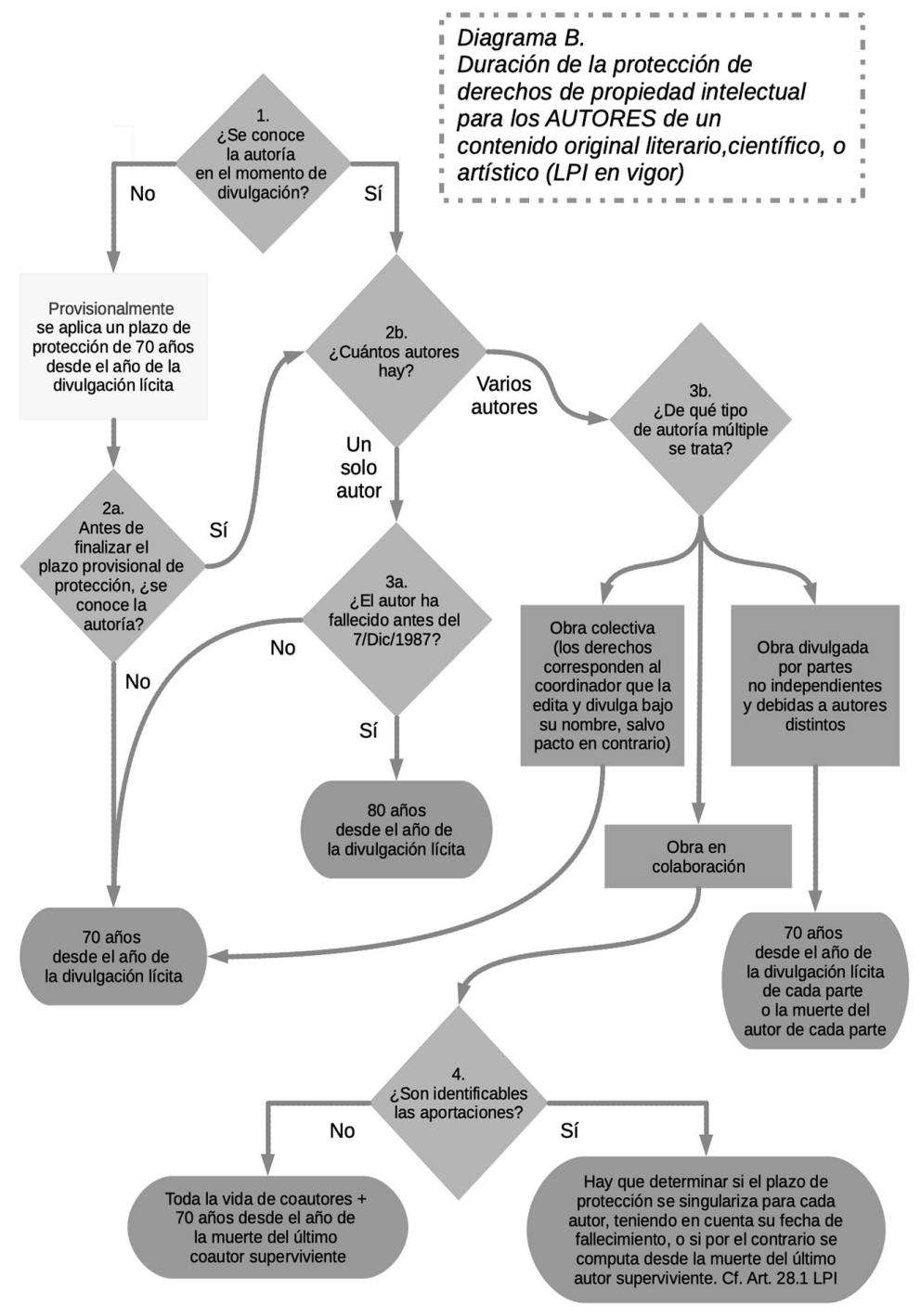

$3 b$.

¿De qué tipo

Un

autor

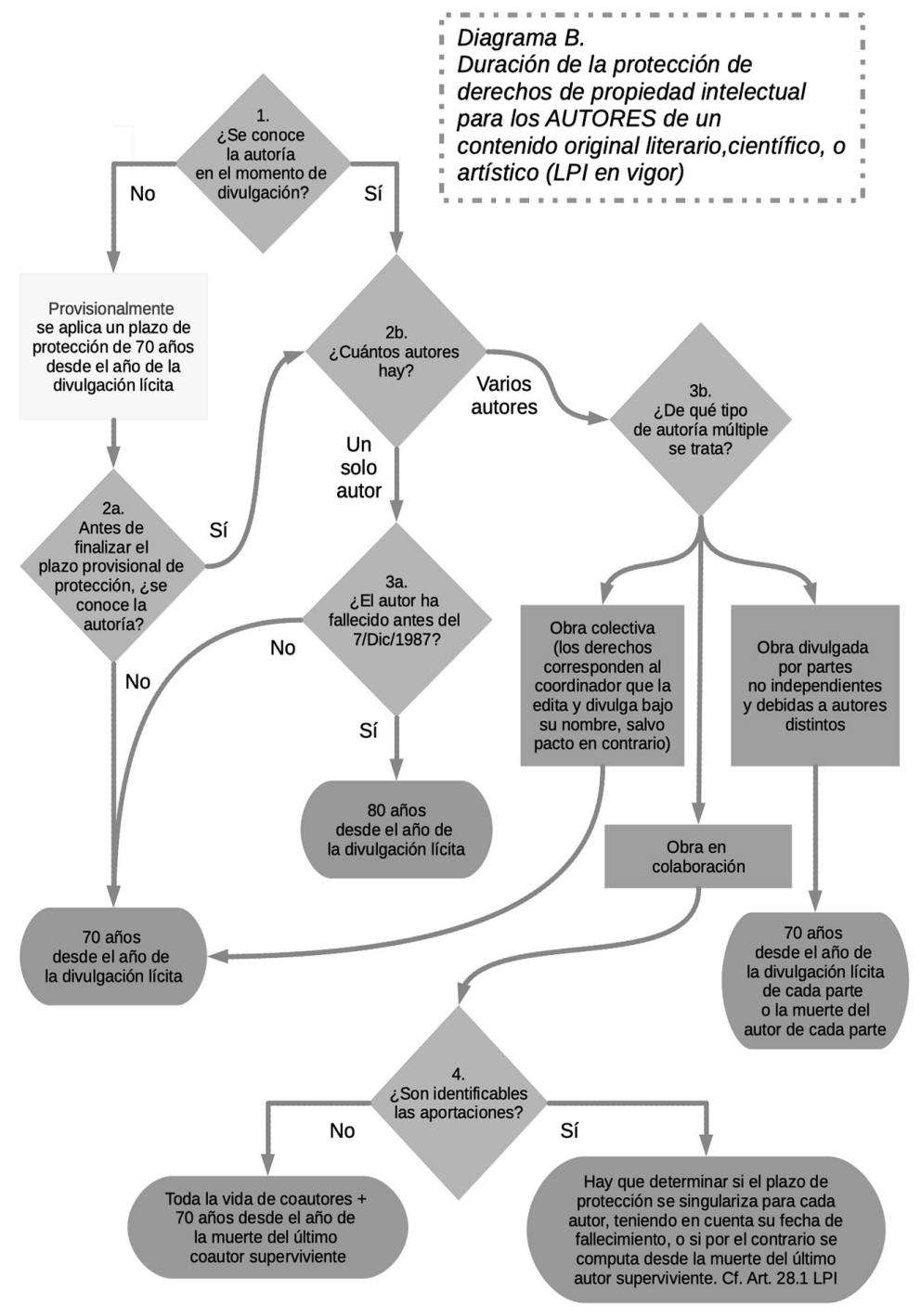




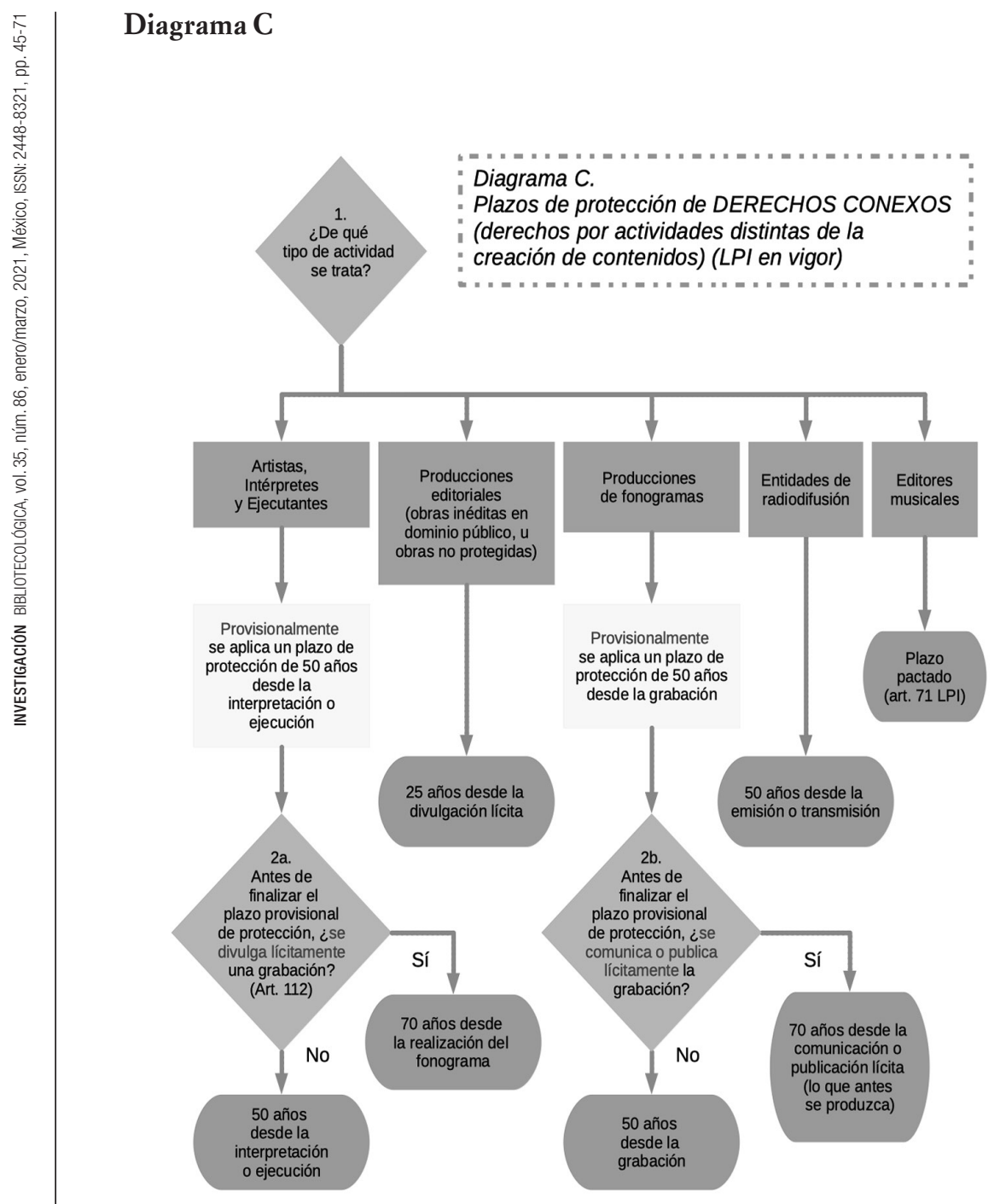




\section{Diagrama D}

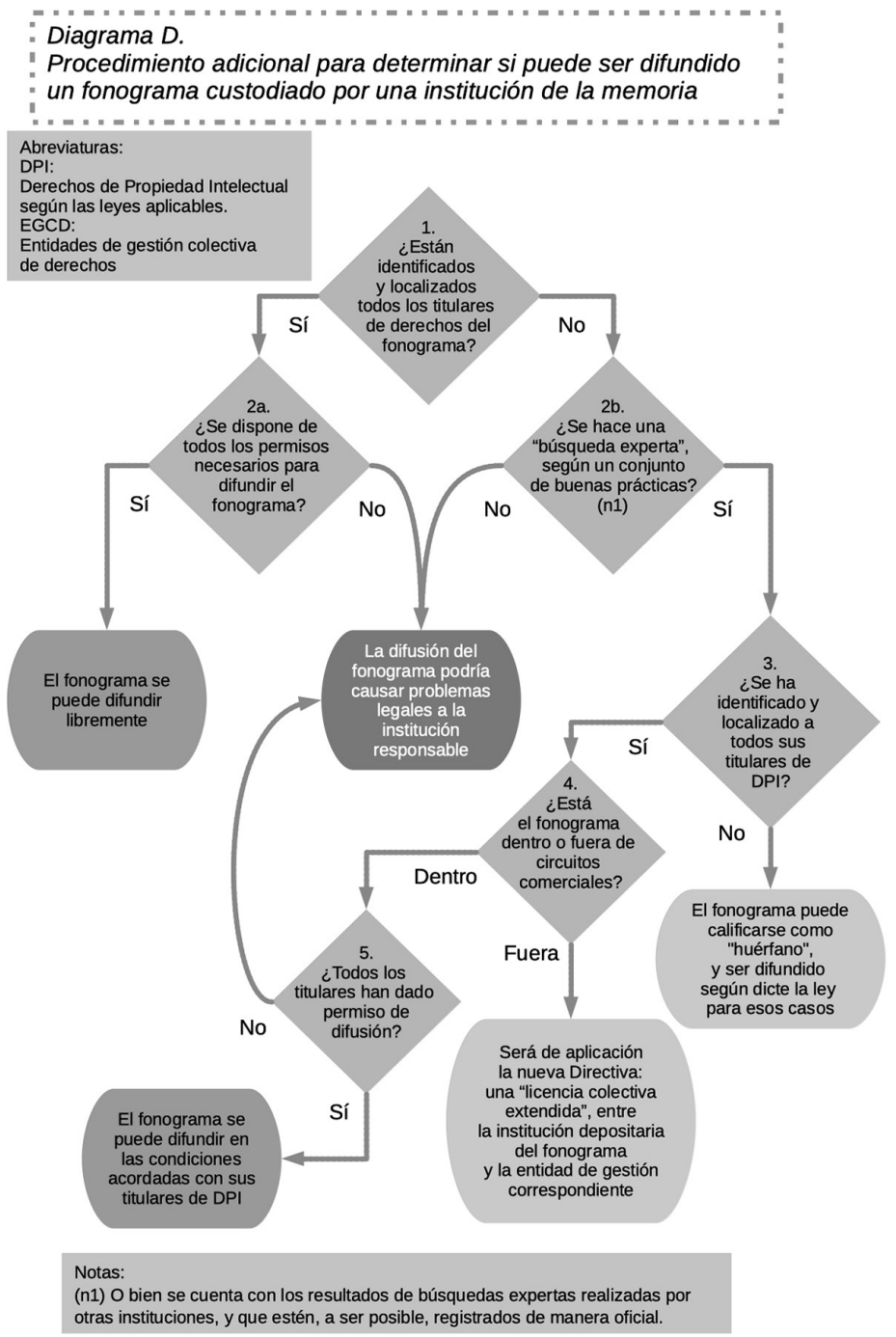

